\title{
An introduction to Acoustic Emission Analysis (AEA) based medical diagnostic techniques: Screening and Monitoring of cartilage defects in knee joint osteoarthrosis
}

\begin{abstract}
Clinical studies have shown that during standardized movements the Acoustic Emission (AE) from lesions in articular cartilage can be assessed. Specific lesions produce specific acoustic signals, therefore it is possible to evaluate the character of cartilage damage. Consequently it is possible to evaluate the condition of the joint cartilage in order to enhance therapy. Patients performed series of knee bends, first on a plane surface in order to assess the cartilage lesions. Then patients performed knee bends on boards simulating orthopaedic insoles by means of inner and outer edge elevations. Insoles aim at relieving the lesioned areas of cartilage from loads and strain. AEA monitoring reveals the effects of a shift of the zone of load transfer immediately and is an adequate tool for the diagnosis as well as the monitoring of therapeutic measures.
\end{abstract}

Keywords: Acoustic Emission Analysis, osteoarthrosis, knee, clinical study, screening of damaged areas, monitoring of load deviation

https://doi.org/10.1515/cdbme-2020-3133

\footnotetext{
*Corresponding author: Subke Joerg: THM University of Applied Sciences, Wiesenstr. 14, D-35390 Giessen, Germany, e-mail: joerg.subke@Ise.thm.de

Krueger Sabine: Osteopathiepraxis, Ludwigsburg, Germany Junker Heinz-Otto: Klinik Rheumazentrum Mittelhessen, Bad Endbach, Germany

Schwalbe Hans-Joachim, Franke Ralf-Peter: BoneDiaS GmbH \& Co.KG, Greifenstein, Germany

Wolf Udo: University of Applied Sciences, Fulda, Germany
}

\section{Introduction}

Knee joint osteoarthrosis is a progressive degenerative disease affecting the knee joint cartilage. Cartilage usually does not heal in humans, therefore an early diagnosis and the possibility of real time screening of defects and monitoring of medical intervention is crucial to the therapeutic measures [1].

Acoustic emission analysis (AEA) in medical diagnosis is a non-destructive method for the screening of the condition of articular cartilage [2], [7]. AEA is carried out during application of standardized loads, because only active defects or deteriorations in cartilage produce acoustic emission. AEA as a medical diagnostic technique can provide a wide scope of information of joint cartilage and its damage patterns [3]. AEA has no known health risks or side effects [4].

In the context of a clinical study 69 patients with the initial clinical diagnosis of knee joint osteoarthrosis underwent a screening with AEA. One exemplary case of a patient with pronounced symptoms in the left knee but unspecific symptoms in the right will serve to illustrate the application of AEA based screening as a diagnostic technique. 


\section{Method}

Clinical studies have shown that during standardized movements the AE from lesions in articular cartilage can be assessed. Different types of lesions emit different acoustic signals, acoustic emission therefore can be assigned to typical lesion patterns. Osteoarthrosis e.g. will emit characteristic AEburst signals. Joints emit a basic continuous background noise. The visually nearly imperceptible movement of a person standing in an upright position is an acoustically very well perceptible load transfer in AEA.

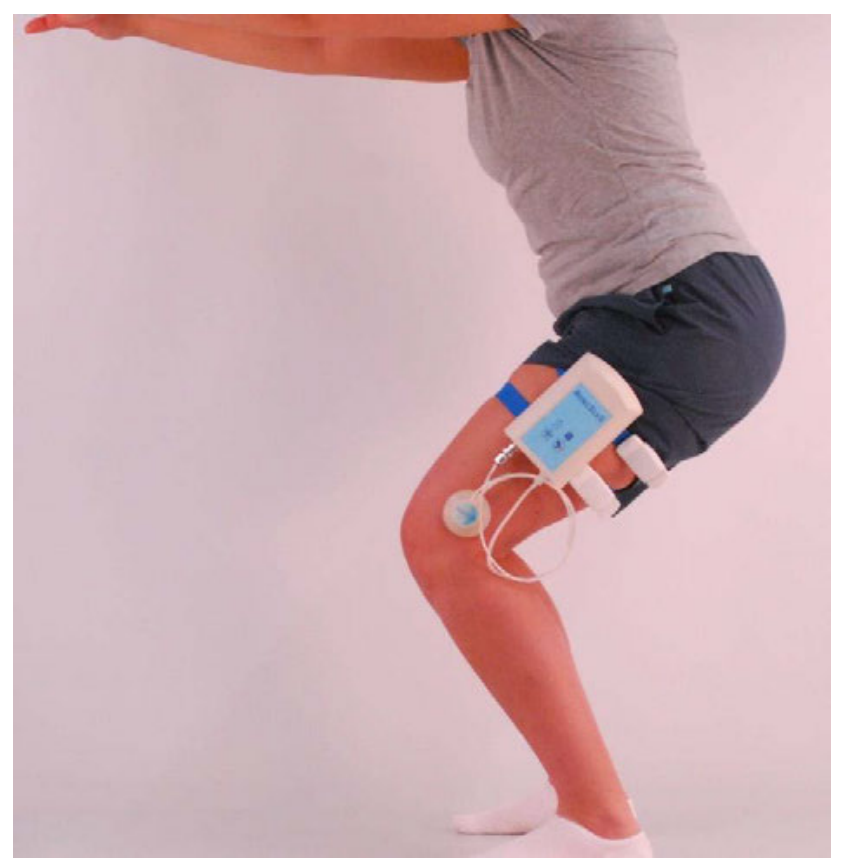

Figure 1: Person during a knee bend with the adapted BoneDiaS-system and piezo sensor at the knee

The standardized movements [5], a series of three knee bends were examined with the help of a BoneDiaS AEA system with an integrated inclinometer. This allows the exact mapping of lesioned or damaged areas on the cartilage surface [6].

The patients perform the first series of knee bends on a plane surface. There will always be variations in the individual performance of the bends which will be registered by the inclinometer. Patients will vary their movements to avoid damaged areas and avoid pain which will enhance the screening of the cartilage (see Figure 1).

The second examination with another series of knee bends will be performed on boards that simulate the effect of orthopaedic insoles with a $2^{\circ}$ inner edge elevation.

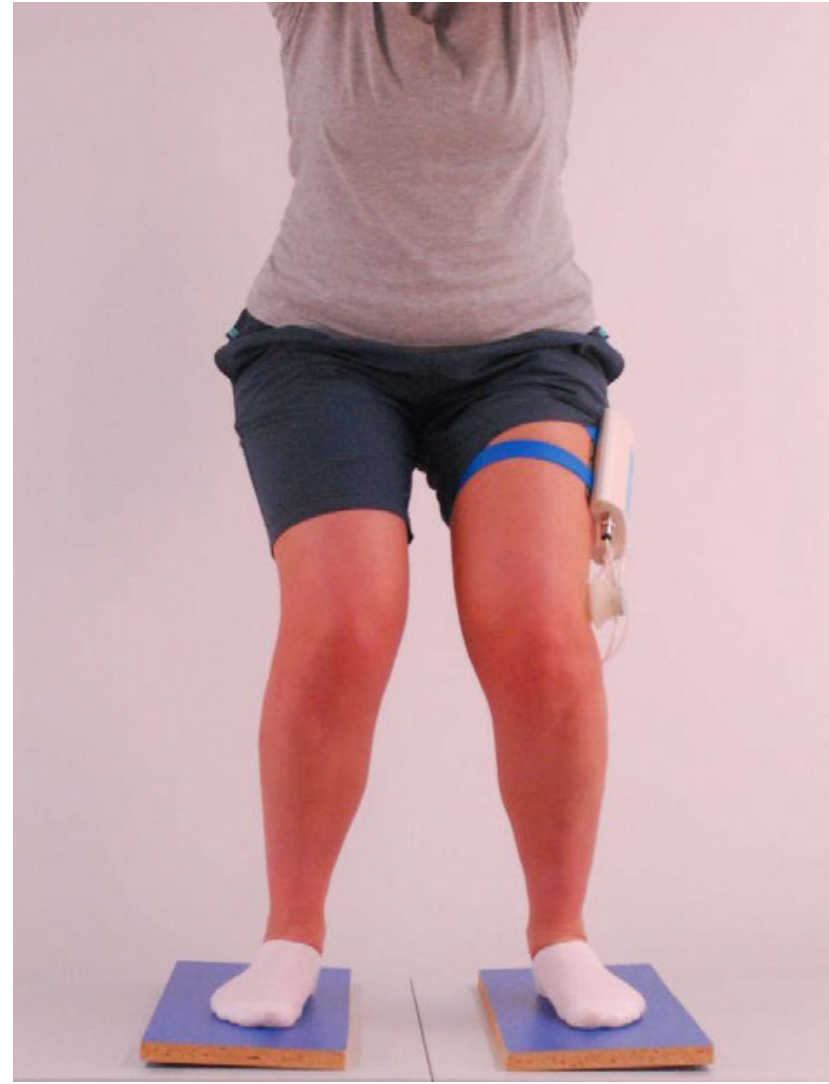

Figure 2: Person during a knee bend on boards with elevated outer edges to simulate insoles

The third series of knee bends will be executed on boards with $2^{\circ}$ outer edge elevations (see Figure 2 ).

By variation of the joint angle position in the sagittal plane with the help of the simulated insoles a shift of the load transfer zone and a rerouting of loads unto undamaged areas is possible. Here again the real time monitoring by AEA provides the necessary information on condition and depth of cartilage.

\section{Results}

The patient of the exemplary case showed distinct acoustic signals of significant damage in the right knee during the performance of the knee bends on the plane surface. See the AE amplitude-time curve with peaks during knee bending S2, $\mathrm{S} 3$ and $\mathrm{S} 6$ for further reference (see Figure 3, 4, 5 and 6).

The examination on the boards when the inner edge was elevated produced pronounced signals while the patient assumed an upright position, but the other acoustic emission was within the normal range in the course of the movement (see Figure 7). 

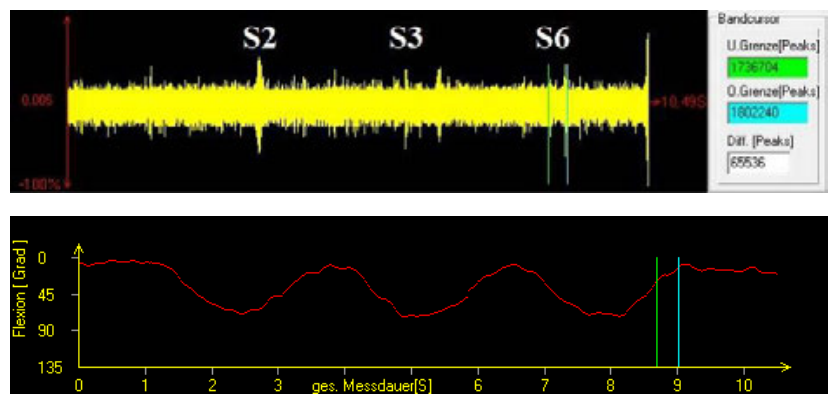

Figure 3: a) AE of the 3 knee bends on a plane surface; location of the signals S2, S3 and S6; b) angle of the 3 knee bends and the location of the signal $\mathrm{S} 6$
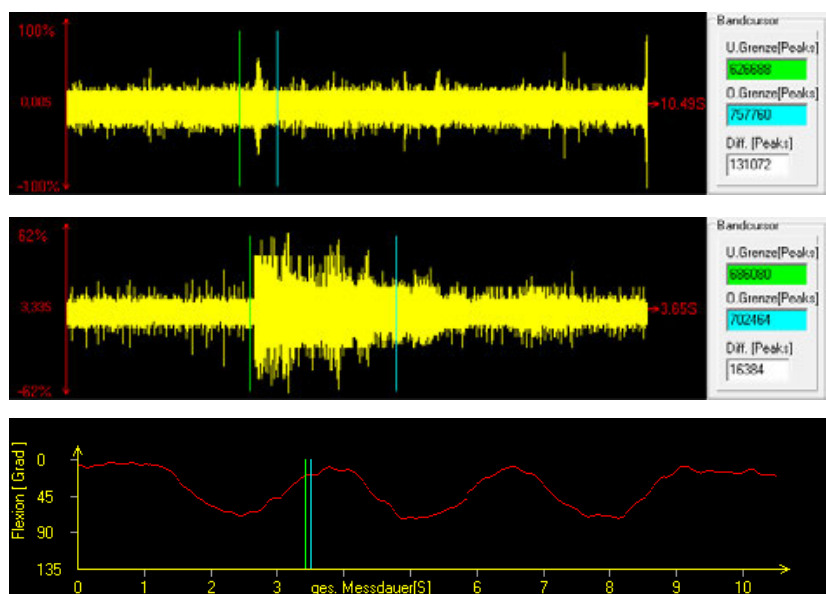

Figure 4: a) $A E$ of the 3 knee bends on a plane surface; b) zoomed location of the signal S2 and c) the location of the signal S2
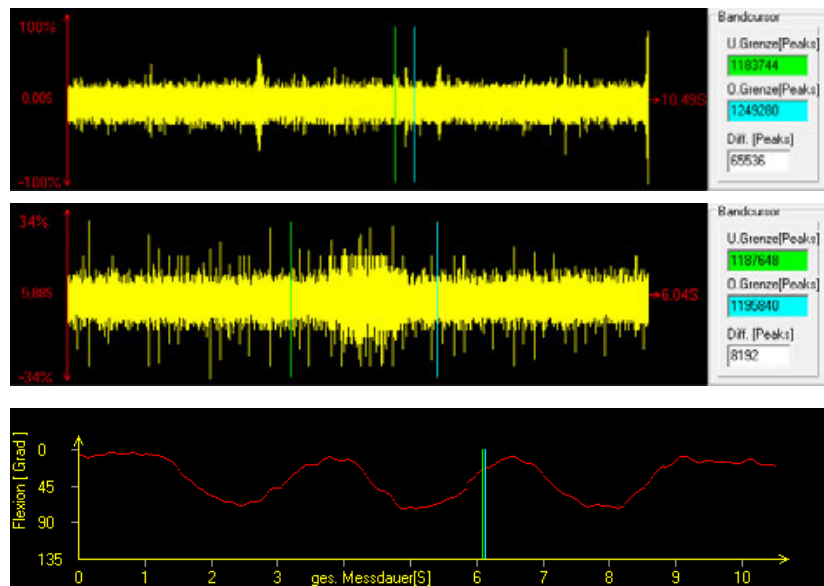

Figure 5: a) AE of the 3 knee bends on a plane surface; b) zoomed location of the signal S3 and c) the location of the signal S3
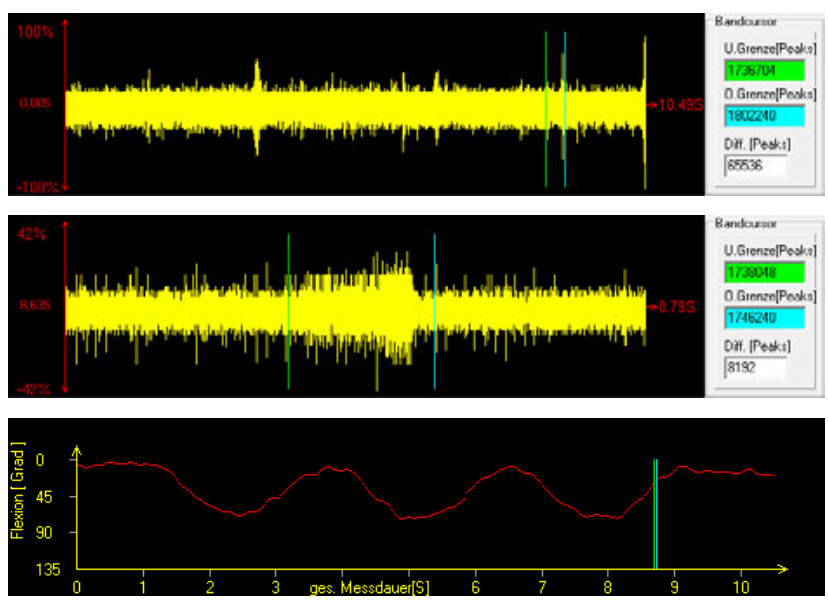

Figure 6: a) AE of the 3 knee bends on a plane surface; b) zoomed location of the signal S6 and c) the location of the signal S6
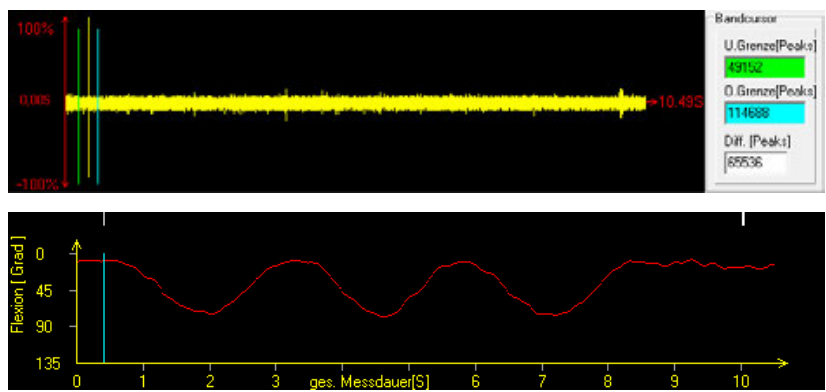

Figure 7: a) $A E$ of the 3 knee bends on surfaces with inner elevations and $b$ ) the trajectory of angle
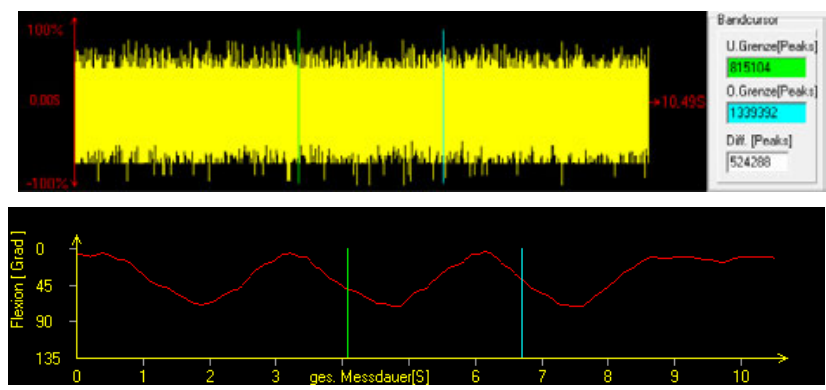

Figure 8: a) $A E$ of the 3 knee bends on surfaces with outer elevations and $b$ ) the trajectory of the angle

The examination on the boards when the outer edge was elevated revealed no acoustic emission significant of damage at all, but the typical acoustic spectrum of the intact joint. In this case the relative presentation of the amplitudes shows a wide band of the noise amplitudes (see Figure 8). 


\section{Discussion}

The AEA of acoustic signals from the exemplary case study of a patient on a plane surface revealed distinct friction signals indicative of damage of the articular cartilage.

The steep rise of the amplitude at the beginning of signal $\mathrm{S} 2\left(1^{\text {st }}\right.$ knee bend, plane surface) actually represents the abrupt entry or drop into a cartilage lesion and at the end the gradual exit out of the lesioned area at a joint angle position of $20^{\circ}$, the patient moving upward into a standing position.

Signal S3 ( $2^{\text {nd }}$ knee bend, plane surface) shows a slightly different load transfer path due to a slight variation in the patient's execution of the knee bend. The joint angle is within the $20^{\circ}$ range but the moderate rise of the amplitude indicates a thicker and healthier layer of cartilage that is dampening the acoustic emission at this point.

Signal S6 ( $3^{\text {rd }}$ knee bend, plane surface) again reveals a distinct friction suggestive of damaged cartilage for the same joint angle position. The inclinometer reveals that in S6 the patient again slightly varied the knee bend.

The AE versus time of signals S2, S3 and S6 reveal that the patient already suffers from degenerative defects of the articular cartilage in the right knee and that the development of osteoarthrosis is imminent. Therefore it is advisable to apply therapeutic measures to stop the progression of the symptoms.

Consequently, the following AEA examinations with simulated insole effects aim at finding healthy areas of joint cartilage and at shifting the load transfer zone from lesioned to un-lesioned areas.

Both alterations, lateral and medial elevation allow to avoid the lesioned areas in the course of the knee bend. With the medial, i.e. inner edge elevation, however, the joint produced pronounced signals while the patient assumed an upright position. Therefore, the lateral, i.e. outer edge elevation has to be preferred. The monitoring of the insoles' effect can be assessed in real time again by AEA.

\section{Conclusion}

The application of different test boards in the course of an AEA screening proves that the contact area between femur and tibia can be examined (real time) in the active joint in order to detect and map the cartilage surface and probable cartilage defects.

In the exemplary case it was possible to find an area of undamaged cartilage onto which the effect of an insole with an outer edge elevation rerouted the load transfer. This avoided a further deterioration of the lesioned area and restored the patient's mobility.

\section{Author Statement}

Research funding: The author state no funding involved. Conflict of interest: Authors state no conflict of interest. Informed consent: Informed consent has been obtained from all individuals included in this study. Ethical approval: The research related to human use complies with all the relevant national regulations, institutional policies and was performed in accordance with the tenets of the Helsinki Declaration, and has been approved by the authors' institutional review board or equivalent committee.

\section{References}

[1] Schwalbe HJ, Bamfaste G, Franke RP. Non-destructive and non-invasive observation of friction and wear of human joints and of fracture initiation by acoustic emission Proc. Instn Mech Engrs Vol 213 Part H, 1999, 41- 48

[2] Schwalbe HJ, Franke RP, Dörner P, Ziegler B Orthopädische Diagnose des menschlichen Femurs und Kniegelenks mit Hilfe der Schallemissionsanalyse. Deutsche Gesellschaft für zerstörungsfreie Prüfung 14. Kolloquium Schallemission, Berichtsband 2003.

[3] Franke RP, Schwalbe HJ, Kiselev J, Wolf U, Subke J, Ziegler B. Schallemissionsanalyse zum Nachweis von Gelenkdefekten in der medizinischen Diagnostik. Deutsche Gesellschaft für zerstörungsfreie Prüfung 18. Kolloquium Schallemission, Berichtsband 2011.

[4] Schwalbe HJ, Franke RP, Dörner P, Kiselev J, Wolf U, Subke J, Ziegler B. Nachweis der Rissbildungsgrenze des humanen Femurs mit Hilfe der Schallemissionsanalyse (SEA). Deutsche Gesellschaft für zerstörungsfreie Prüfung 18. Kolloquium Schallemission, Berichtsband 2011.

[5] Titze M. Schallemissionsanalys als Nachweis des Reibverhaltens im menschlichen Kniegelenk in verschiedenen Belastungssituationen. Diplomarbeit FB Maschinenbau und Feinwerktechnik, FH-Gießen-Friedberg, 1996.

[6] Schwalbe HJ, Schmale J, Subke J, Ziegler B, Kellotat A, Dörner P, Franke RP, Wolf U. Detection of Defects in the Human Skeletal System and Production of Failure Optimized Artificial Bone Applying Acoustic Emission Analysis (AEA). $31^{\text {st }}$ Conference of the European Working Group on Acoustic Emission (EWGAE) Proceedings, Dresden 2014

[7] Kiselev J, Wolf U, Ziegler B, Schwalbe H-J, Franke R-P. Detection of early phases os ostearthritis using acoustic emission analysis. Med. Eng. Phys. 2019, 65, 57-60. 